\title{
Registro de Isogonoceraia divergipennis White \& Hodkinson associado a Poincianella pluviosa (Fabaceae) em Mato Grosso, Brasil
}

\author{
Record of Isogonoceraia divergipennis White ↔. Hodkinson associated \\ with Poincianella pluviosa (Fabaceae) from Mato Grosso, Brazil
}

\section{Tatiana Mazzardo ${ }^{*}$, Marliton Rocha Barreto², Leonir Antunes Pezzini ${ }^{1}$, Alisson Diego Bassoli Sedano ${ }^{1}$, Daniel Burckhardt ${ }^{3}$, Dalva Luiz de Queiroz ${ }^{4}$}



RESUMO: A ocorrência de Isogonoceraia divergipennis (Hemiptera: Psyllidae) foi constatada no estado de Mato Grosso, associada a Poincianella pluviosa (Fabaceae). Até o momento a distribuição da $I$. divergipennis estava restrita aos estados da Bahia, Minas Gerais, Paraná e São Paulo e esse resultado amplia a área de distribuição do inseto para a região centro-oeste do Brasil. O material de estudo foi obtido em Sorriso, Mato Grosso (S12³2'42,78”, W5543'32,10”) e as coletas foram realizadas no período de setembro de 2013 a maio de 2014 .

PALAVRAS-CHAVE: distribuição; Psylloidea; planta hospedeira.
ABSTRACT: Isogonoceraia divergipennis (Hemiptera: Psyllidae) associated with Poincianella pluviosa (Fabaceae) was recorded in the state of Mato Grosso, Brazil, for the first time. Previously, I. divergipennis was known only in the states of Bahia, Minas Gerais, Paraná and São Paulo. Our results extend the known area of distribution of the insect to central-western Brazil. The studied material was from Sorriso, Mato Grosso (S12³2'42.78”, W5543'32.10”), collected from September 2013 to May 2014.

KEYWORDS: distribution; Psylloidea; host plant.

'Universidade Federal de Mato Grosso (UFMT) - Sinop (MT), Brasil.

${ }^{2}$ Núcleo de Estudos da Biodiversidade da Amazônia Mato-grossense; Instituto de Ciências Naturais, Humanas e Sociais; UFMT - Sinop (MT), Brasil.

${ }^{3}$ Naturhistorisches Museum - Basel, Switzerland.

${ }^{4}$ Embrapa Florestas - Colombo (PR), Brasil.

*Autor correspondente: tatymazzardo@hotmail.com

Recebido em: 04/08/2014. Aceito em: 09/12/2015 
O gênero Isogonoceraia pertence à família Psyllidae (Ciriacreminae), e contém duas espécies descritas e várias espécies neotropicais não descritas. A primeira espécie descrita foi Isogonoceraia venusta Tuthill, relatada nas Ilhas Marianas (Pacifico) (Tuthill, 1964; Ouvrard, 2014). BurckHardt; Queiroz (2012) constataram a ocorrência de duas espécies desse gênero no Brasil, sendo a primeira espécie ainda não descrita e uma segunda espécie que será foco deste trabalho.

O material de estudo foi obtido na área urbana do município de Sorriso, Mato Grosso (S12³2'42,78”, W55'43'32,10"). As coletas foram realizadas no decorrer dos meses de setembro de 2013 a maio de 2014, com autorização sob licença do Instituto Brasileiro do Meio Ambiente e dos Recursos Naturais Renováveis (IBAMA) e do Sistema de Autorização e Informaçáo em Biodiversidade (SISBIO) número 13362. O material foi coletado com o auxílio de rede entomológica e armazenado em frascos contendo álcool 70\%, sem desnaturante e devidamente etiquetados. Os insetos foram triados com o auxílio de microscópio estereoscópico e depositados no Acervo Biológico da Amazônia Meridional (ABAM) na Universidade Federal de Mato Grosso (UFMT), Campus Sinop. Com o procedimento foi possível identificar a presença de exemplares da espécie Isogonoceraia divergipennis (Fig. 1).

Os psilídeos possuem 1 a $10 \mathrm{~mm}$ de comprimento, antenas normalmente contendo 10 segmentos, rostro curto, asas membranosas e pernas posteriores saltatórias. São ovíparos, fitófagos, eliminam substâncias açucaradas e precisam de uma planta hospedeira. A espécie $I$. divergipennis foi descrita por White e Hodkinson em 1980, e tem como características gerais: cabeça fortemente deflexa,
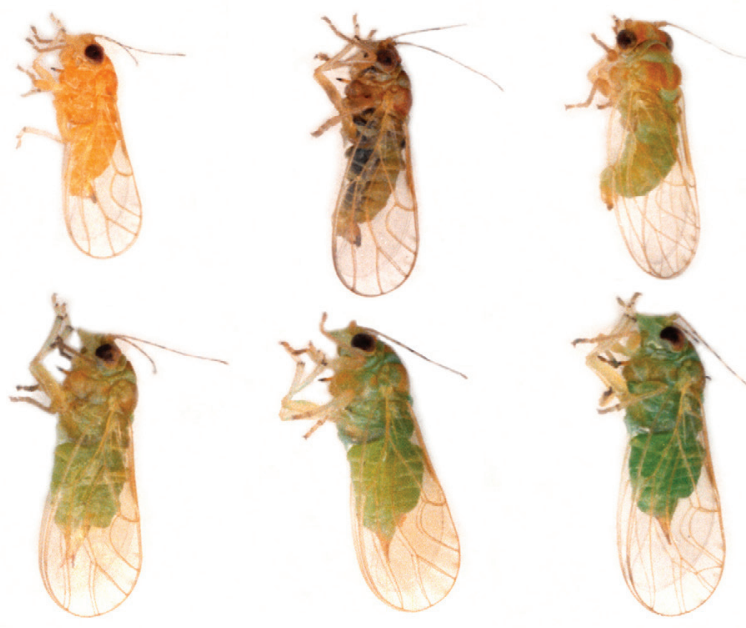

Figura 1. Adultos de Isogonoceraia divergipennis, mostrando a diversidade de cores apresentada pelo inseto. com vértice relativamente longo, antena inserida no topo do vértex e com 10 segmentos. Tórax com pronoto curto, quase vertical, propleurito dividido por uma sutura vertical. Asas anteriores membranosas, subapicalmente expandidas, porém mais amplas no terço apical, pteroestigma rudimentar, com o rebordo costal quase em linha reta na região mediana.

Segundo Burckhardt; QueIroz (2012), I. divergipennis possui como planta hospedeira a Poincianella pluviosa (Fabaceae) (Fig. 2), conhecida popularmente por sibipiruna, planta nativa do Brasil, alocada principalmente na Mata Atlântica do Rio de Janeiro, sul da Bahia e no Pantanal Matogrossense, que provoca danos em suas folhas (Fig. 3). Sua utilização se dá especialmente para compor o paisagismo urbano, porém, também é indicada para recuperação de áreas degradadas e composiçẫo de parques e jardins. De sua madeira provêm caibros e ripas que podem ser utilizados na construçáo civil ou de móveis (LORENZI, 2009).

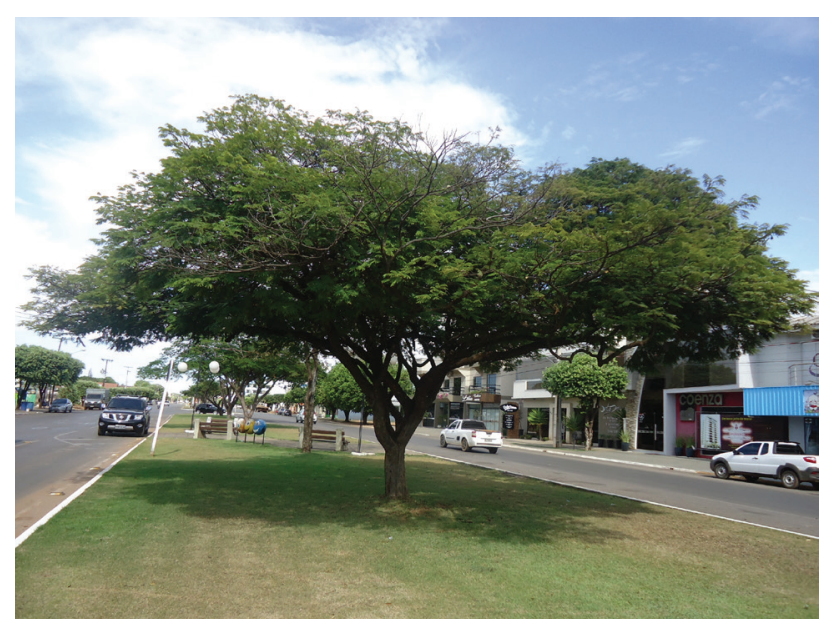

Figura 2. Poincianella pluviosa (Fabaceae). Planta hospedeira de Isogonoceraia divergipennis.

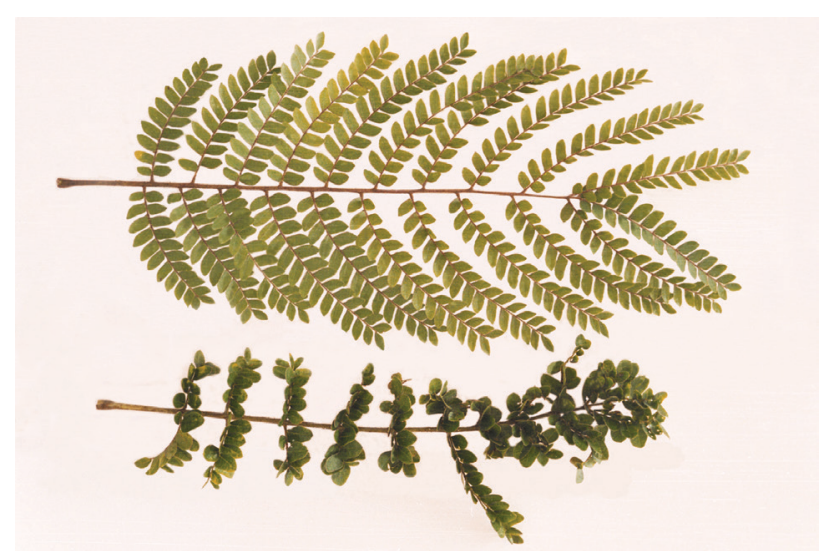

Figura 3. Danos provocados por Isogonoceraia divergipennis em folhas de Poincianella pluviosa. 


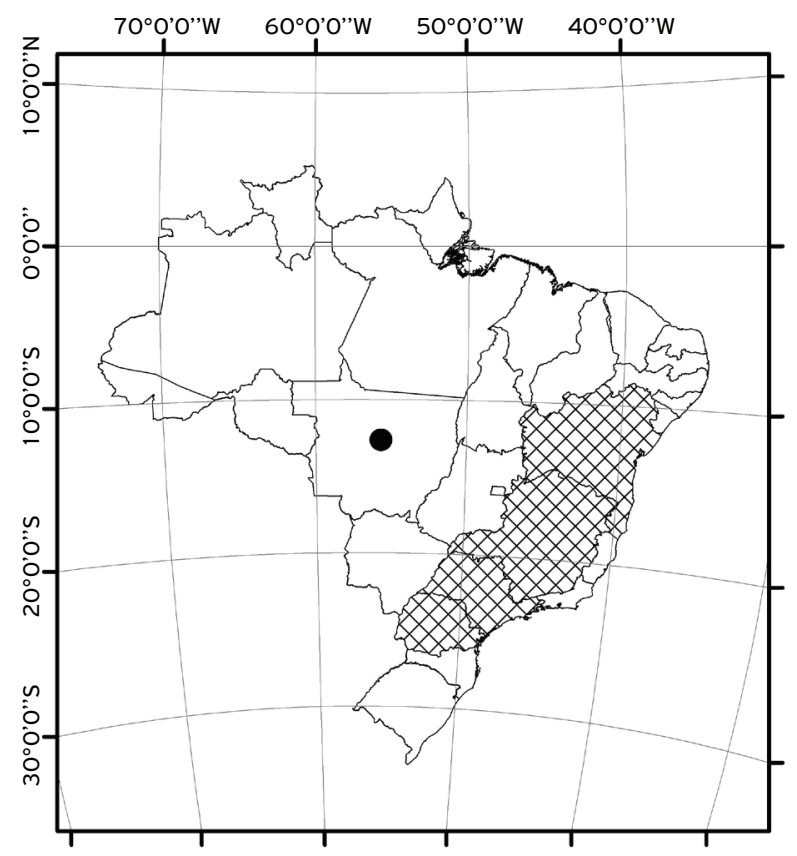

Fonte do mapa: IBGE.

Área hachurada: estados (SP, MG, BA, PR) com ocorrência da espécie.

- Local de ocorrência no estado de Mato Grosso.

Figura 4. Distribuição de Isogonoceraia divergipennis no Brasil.
A distribuição geográfica da espécie I. divergipennis estava restrita aos estados da Bahia, Minas Gerais, Paraná e São Paulo (BurcKhardT; QueIroz, 2012). A constatação da presença do inseto no município de Sorriso, Mato Grosso, amplia sua distribuição (Fig. 4).

$\mathrm{O}$ estudo com Isogonoceraia divergipennis amplia a distribuiçâo do inseto para a regiáo centro-oeste do Brasil associado à $P$. pluviosa e ressalta que as características provenientes da infestação dessa espécie de psilídeo em sua hospedeira são indesejáveis, pois afetam o desenvolvimento da planta (Fig. 2B) e sua beleza paisagística. Neste trabalho também foi possível observar que o inseto produz excrementos pegajosos em forma de gotículas transparentes (melada) e sua numerosa população causa deformaçôes nas folhas da planta hospedeira.

\section{AGRADECIMENTOS}

Ao projeto "Manejo e biodiversidade de Psylloidea associados ao sistema integração lavoura-pecuária-floresta e à citricultura no Brasil" pelo apoio logístico e financeiro.

| | | | | | | | | | | | | | | | | | | | | | | | | | | | | | | | | | | | | | | | | | | | | | | | | | | | | | | | | | | | | | | | | | | | | | | | | | | | | | | | | | | | | | | | | | | | | | | | | | | | | | | | | | | | | | | | | | | | | | | | | | | | | | | | | | | | | | | | | | | | | | | | | | | | | | | | | | | | | | | | | | | | | | | | | | | | | | | | | | | | | | | | | | | | | | | | | | | | | | | | | | | | | | | | | | | | REFERÊNCIAS

BURCKHARDT, D.; QUEIROZ, D.L. Checklist and comments on the jumping plant-lice (Hemiptera: Psylloidea) from Brazil. Zootaxa, v. 3571 , p. 26-48, 2012.

LORENZI, H. Árvores brasileiras: manual de identificação e cultivo de plantas arbóreas nativas do Brasil. Nova Odessa: Instituto Plantarum, 2009. 384p.

OUVRARD, D. Psyl'list: the world Psylloidea database. Disponível em: <http://www.hemiptera-databases.com/psyllist>. Acesso em: 10 jun. 2014.
TUTHILL, L.D. Insects of Micronesia: Homoptera: Psyllidae. Insects of Micronesia, v.6, n.6, p.353-376, 1964.

WHITE I.M.; HODKINSON I.D. New psyllids (Homoptera, Psylloidea) from the cocoa region of Bahia, Brazil. Revista Brasileira de Entomologia, v.24, n.2, p.75-84, 1980. 